\title{
Correction to: Effectiveness and tolerability of lidocaine $5 \%$ spray in the treatment of lifelong premature ejaculation patients: a randomized single-blind placebo-controlled clinical trial
}

\section{Mohammed Abu El-Hamd}

Published online: 22 January 2020

(c) The Author(s), under exclusive licence to Springer Nature Limited 2020

\section{Correction to: International Journal of Impotence Research https://doi.org/10.1038/s41443-019-0225-9}

In the published article the following incorrect statement appeared in the Patients and methods section:

Group $1(n=75)$; was given on demand lidocaine $5 \%$ spray for 8 weeks (One to two applications $(1-2 \mathrm{ml})$ of lidocaine $5 \%$ sprays; contain 5-10 mg of lidocaine, in a metered-dose aerosol-delivery system) (Lidocaine topical aerosol U.S.P. 38, The Arab Drug Co, Cairo, Egypt). Group $2(n=75)$; was given placebo in the form on demand alcohol spray for 8 weeks (One to two applications (1-2 ml) of alcohol $40 \%$ sprays).
The statement should read as follows:

Group $1(n=75)$; was given on demand lidocaine $5 \%$ spray for 8 weeks (One to two applications $(0.1-0.2 \mathrm{ml})$ of lidocaine $5 \%$ sprays; contain $5-10 \mathrm{mg}$ of lidocaine, in a metered-dose aerosol-delivery system) (Lidocaine topical aerosol U.S.P. 38, The Arab Drug Co, Cairo, Egypt). Group $2(n=75)$; was given placebo in the form on demand alcohol spray for 8 weeks (One to two applications $(0.1-0.2 \mathrm{ml})$ of alcohol $40 \%$ sprays).

This has been corrected in both the PDF and HTML versions of the Article. 